\title{
POTENSI PEMBENTUKAN LAPISAN SUPER DAN ULTRA KERAS SENYAWA KOMPOSIT NITRIDA MENGGUNAKAN KAIDAH ELEKTRODEPOSISI
}

\author{
Esmar Budi1, a) \\ ${ }^{1}$ Program Studi Fisika dan Pendidikan Fisika FMIPA, Universitas Negeri Jakarta \\ Jl. Pemuda No 10, Jakarta 13220 \\ Email: a)esmarbudi@unj.ac.id
}

\begin{abstract}
Abstrak
Komposit senyawa nitrida super dan ultra keras memiliki potensi untuk menggantikan material intan dalam berbagai aplikasi mekanik. Tingkat kekerasan super dan ultra lapisan komposit senyawa nitrida diperoleh melalui pembentukan struktur nano yang mampu mempertahankan tingkat kekerasan tinggi hingga suhu aplikasi mencapai $1100{ }^{\circ} \mathrm{C}$. Pembentukan struktur nano terjadi melalui segregrasi fase spontan secara termodinamika antara butir fase kristal nitrida dan matrik fase amorf nitrida. Salah satu komposit senyawa nitrida super dan ultra keras adalah TiAlN $/ \mathrm{Si}_{3} \mathrm{~N}_{4}$ dengan TiAlN sebagai fase kristal dan $\mathrm{Si}_{3} \mathrm{~N}_{4}$ sebagai amorf. Senyawa TiAlN memiliki keunggulan dibandingkan dengan senyawa nitrida lain terutama tingkat kekerasan yang tinggi serta ketahana aus dan korosi suhu tinggi hingga $700{ }^{0} \mathrm{C}$. Aplikasi senyawa nitrida dilakukan melalui pembentukan lapisan tipis komposit menggunakan kaidah deposisi. Namun demikian kaidah ini relatif mahal dan rumit karena memerlukan kondisi ruang hampa. Kaidah lain yang relatif lebih murah, mudah dan cepat dalam pembentukan lapisan komposit senyawa nitrida adalah kaidah elektrodeposisi yang bekerja berdasarkan prinsip elektrokimia. Telah dilakukan kajian awal pembentukan lapisan tipis komposit Ni-TiAlN menggunakan kaidah elektrodeposisi. Logam nikel (Ni) digunakan sebagai matrik karena sifat ketahanan korosi yang baik. Komposisi, morfologi dan struktur kristal serta ketahanan korosi lapisan komposit dipengaruhi oleh parameter elektrodeposisi seperti arus elektrodeposisi dan konsentrasi partikel TiN dan AlN. Pembentukan lapisan komposit Ni$\mathrm{TiAlN} / \mathrm{Si}_{3} \mathrm{~N}_{4}$ mennggunakan kaidah elektrodeposisi berpotensi menghasilkan lapisan komposit nitrida super dan ultra keras.
\end{abstract}

Kata-kata kunci: Senyawa nitrida super dan ultra keras, lapisan komposit nikel-nitrida, elektrodeposisi.

\begin{abstract}
Super and ultra hard nitride compound composite has potency to replace the diamond material in various mechanical applications. The violence level of super and ultra composite layer of nitride compound is obtained through nanostructures formation were able to maintain high levels of violence until the temperature reached $1100{ }^{\circ} \mathrm{C}$. The formation of nanostructures occur through spontaneous phase segregation thermodynamically between nitride crystal phase grains and amorphous nitride phase matrix. One of super and ultra hard nitride compound compisite is $\mathrm{TiAlN} / \mathrm{Si}_{3} \mathrm{~N}_{4}$ by $\mathrm{TiAlN}$ as crystal phase and $\mathrm{Si}_{3} \mathrm{~N}_{4}$ as amorf. TiAlN compound has exellence compared to other nitride compound expecially high degree of violence and wear resistance and high temperature corrosion untill $700{ }^{0} \mathrm{C}$. Applications nitride compound through forming a thin layer of composite use deposition methode. However this methode relatively expensive and complicated because it requires a vacuum condition. Another methode that relatively cheaper, easier and faster in the formation of the composite layer of nitride compound is electrodeposition methode that works on the principle of electrochemistry. Initial study of formation Ni-TiAlN thin layer composite that use electrodeposition has been done. nickel
\end{abstract}


metal (Ni) is used as a matrix because good corrosion resistance properties. The composition, morphology, crystal structure, and the corrosion resistance of composite layer are affected by electrodeposition parameters such as electrodeposition current and the concentration of particles TiN and AlN. The formation of the composite layer $\mathrm{Ni}-\mathrm{TiAlN} / \mathrm{Si}_{3} \mathrm{~N}_{4}$ using electrodeposition methode potentially resulting super and ultra hard nitride composite layer.

Keywords: Super and hard nitride compound, nickel-nitride composite layer, electrodepisition.

\section{PENDAHULUAN}

Material keras hingga super keras dan ultra keras banyak dimanfaatkan sebagai perkakas maupun senjata dalam setiap peradaban manusia mulai dari jaman batu, kayu, tulang, gading hingga logam [1]. Di awal jaman logam, perunggu memainkan peran penting sebagai material perkakas sebelum kemudian digantikan oleh baja hingga kemudian ditemukannya material paling keras intan yang pemanfaatnya dilakukan secara industri. Bahkan intan dipercaya merupakan material abad 21 dikarenakan keunggulan sifat-sifatnya [2]. Seperti yang telah diketahui bahwa intan sebagai material alotropik dari karbon kubus dikenal sebagai material paling keras yang banyak dimanfaatkan dalam keperluan operasi industri sebagai perkakas potong bubut (turning dan milling) maupun mata bor. Akan tetapi, intan memiliki keterbatasan suhu pemakaian dimana intan mengalami reaksi oksidasi pada suhu $600{ }^{\circ} \mathrm{C}$, dapat berubah menjadi heksagonal karbon pada suhu $900{ }^{\circ} \mathrm{C}$ serta mengalami reaksi degradasi dengan paduan logam seperti baja dan nikel melalui pembentukan pembentukan karbida. Sehingga penggunaan intan menjadi terbatas hanya pada suhu sedang dan hanya untuk material bukan logam saja. Untuk itu dilakukan sintesis senyawa intan sintetis guna mengatasi hal tersebut dengan salah satunya adalah senyawa nitrida.

\section{MATERIAL}

\subsection{Senyawa Nitrida}

Salah satu senyawa nitrida yang banyak dimanfaatan dalam operasi industri adalah senyawa TiAlN. Senyawa TiAlN sebagai salah satu logam transisi nitrida memiliki kekerasan yang tinggi serta kestabilan termal dan ketahanan korosi yang tinggi [3]. Secara umum struktur kristal TiAlN adalah kristal kubus pusat muka (fase $(\mathrm{Ti}, \mathrm{Al}) \mathrm{N})$ dan heksagonal (fase AlN) [4]. Pencapaian tertinggi sifat kekerasan lapisan logam transisi nitrida diperoleh melalui pembentukan lapisan super dan ultra keras (TiAl) $\mathrm{N} / \mathrm{Si}_{3} \mathrm{~N}_{4}$ dengan nilai kekerasan mendekati kekerasan intan dengan kestabilan termal hingga suhu $1200^{\circ} \mathrm{C}[5,6]$. Nilai kekerasan lapisan TiAlN secara umum bersumber dari tegangan kompresif sisa yang akan berkurang saat lapisan diaplikasikan pada suhu tinggi. Namun pembentukan lapisan TiAlN yang dikombinasikan dengan $\mathrm{Si}_{3} \mathrm{~N}_{4}$ mampu mempertahankan kekerasan meskipun pada aplikasi suhu tinggi. Hal ini disebabkan oleh pengaturan sendiri (self-organization) struktur nano lapisan sebagai hasil dari segregasi fase secara termodinamika [7]. Selain itu lapisan TiAlN memiliki kestabilan terhadap oksidasi hingga suhu $800^{\circ} \mathrm{C}$ melalui pembentukan lapisan pasif oksida (AlTiO) [8].

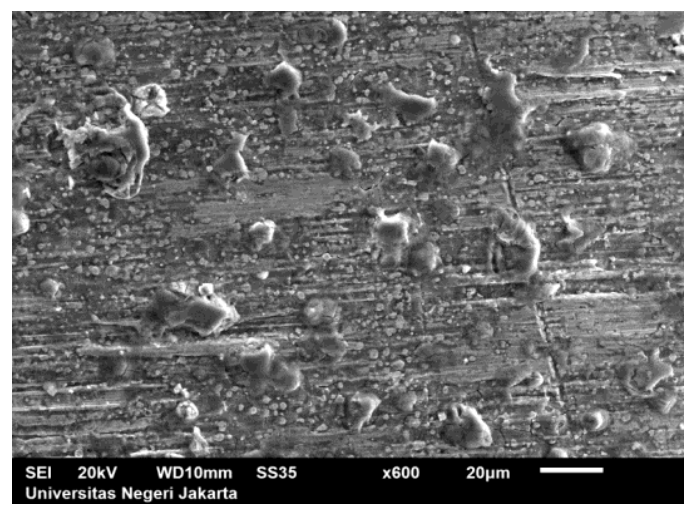

Gambar 1. Morfologi permukaan lapisan TiAIN pada baja HSS [9]. 
Senyawa nitrida keras lain adalah senyawa $\mathrm{Si}_{3} \mathrm{~N}_{4}$ yang merupakan senyawa keramik dengan sifat mekanik, kestabilan kimia, dan konduktivitas termal yang baik khususnya pada suhu tinggi. Secara umum senyawa $\mathrm{Si}_{3} \mathrm{~N}_{4}$ merupakan senyawa kovalen bersifat polimorf heksagonal $\alpha-\mathrm{Si}_{3} \mathrm{~N}_{4}$ dan $\beta-\mathrm{Si}_{3} \mathrm{~N}_{4}$ dengan $\beta-\mathrm{Si}_{3} \mathrm{~N}_{4}$ merupakan fase yang lebih stabil. Secara umum serbuk senyawa $\mathrm{Si}_{3} \mathrm{~N}_{4}$ dipadatkan melalui mekanisme sintering dengan menambahkan beberapa oksida pada permukaan partikel $\mathrm{Si}_{3} \mathrm{~N}_{4}$ untuk membentuk fase cair yang kemudian memadat melalui mekanisme penyusunan kembali partikel-partikel dan presipitasi larutan selama proses sintering. Setelah proses sintering selesai fase cair berubah menjadi fase glass atau kristalin sebagian (oksinitrida) pada material tersinter sehingga hadir sebagai fase kedua yang terisolasi. Fase kedua ini hadir sebagai cacat pada butir $\mathrm{Si}_{3} \mathrm{~N}_{4}$. Hantaran kalor pada partikel $\mathrm{Si}_{3} \mathrm{~N}_{4}$ terjadi melalui mekanisme fonon, maka cacat kristal pada senyawa $\mathrm{Si}_{3} \mathrm{~N}_{4}$ mengimbas hamburan fonon sehingga menurunkan konduktivitas termal. Kehadiran oksigen pada kristal $\mathrm{Si}_{3} \mathrm{~N}_{4}$ menghasilkan kekosongan posisi $\mathrm{Si}$ pada kisi kristal sehingga dapat menghamburkan fonon. Partikel $\mathrm{Si}_{3} \mathrm{~N}_{4}$ merupakan partikel lebam dikarenakan titik lelehnya yang tinggi [10]. Tingkat kekerasan $\mathrm{Si}_{3} \mathrm{~N}_{4}$ mampu mencapai nilai $35 \mathrm{GPa}$, kerapatan $3.44 \mathrm{gr} / \mathrm{cm}^{3}$ dan koefisien termal 1.4-3.7 x $10^{-6} /{ }^{0} \mathrm{~K}$. Dengan sifat-sifat tersebut, senyawa ini banyak dijadikan sebagai partikel penguat pada sistem komposit.

Pembentukan senyawa lapisan super keras $\mathrm{TiAlN} / \mathrm{Si}_{3} \mathrm{~N}_{4}$ mengunakan kaidah deposisi menghasilkan tingkat kekerasan intan dengan kestabilan termal pada suhu tinggi. Hal ini terjadi melalui mekanisme segregasi fase secara termodinamika yang membawa pembentukan struktur nano secara spontan $[6,11]$. Struktur nano yang terbentuk adalah butir kristal nitrida (TiAlN) dikelilingi oleh matrik nitrida amorf $\left(\mathrm{Si}_{3} \mathrm{~N}_{4}\right)$ [12]. Segregasi fase spontan tanpa melibatkan pengintian fase lain mengakibatkan terbentuknya komposit nano melalui pengaturan sendiri dengan ukuran kristal ditentukan kesetimbangan antara penurunan energi bebas akibat segreasi fase, penurunan sifat kimiawi serta regangan tak koheren antarmuka. Komposit nano yang terbentuk, stabil terhadap pertumbuhan butir pada suhu tinggi [6].

Konsep peningkatan kekerasan lapisan komposit melalui pembentukan struktur nano dari sistem kombinasi butir kristal dan amorf adalah mengingat bahwa dislokasi tidak ada dalam kristal nano dan jika ada maka dislokasi tidak dapat bergerak pada matrik amorf [12]. Sistem material yang memiliki kemampuan kuat untuk terjadinya segregasi secara termodinamika adalah sistem tersier ataupun quarter seperti sistem nitrida logam transisi. Secara umum sistem nitrida logam transisi merupakan padatan kuat dan mudah mengkristal meskipun pada suhu yang relatif rendah. Sedangkan senyawa amorf $\mathrm{Si}_{3} \mathrm{~N}_{4}$ banyak digunakan mengingat senyawa ini terbilang kuat dan mampu membentuk jaringan amorf pada sistem komposit.

\subsection{Logam matriks Nikel}

Logam nikel (Ni) dengan paduannya banyak digunakan sebagai logam matriks pada lapisan komposit karena sifat keuletan dan ketahanan korosi yang baik. Struktur kristal nikel adalah FCC dengan titik leleh $1455^{\circ} \mathrm{C}$ [26]. Ketahanan korosi nikel terjadi karena pembentukan lapisan pasif oksida pada permukaannya yang berperan sebagai pelindung terhadap lingkungan korosif. Logam nikel murni, tidak terlindung korosi melalui pembentukan kristal nano melainkan melalui pembentukan lapisan oksida $\mathrm{NiO}$ [13]. Pembentukan lapisan $\mathrm{NiO}$ meningkat seiring dengan peningkatan pembentukan kristal nano.

\section{KAIDAH PELAPISAN}

Kaidah pelapisan senyawa nitrida dapat dilakukan dengan menggunakan kaidah Deposisi Uap Fisik (Physical Vapor Deposition) [9]. Namun demikian proses deposisi kaidah ini terbilang cukup rumit dan mahal karena dilakukan dalam suatu ruang hampa. Kaidah lain yang relatif mudah, murah dan cepat adalah elektrodeposisi menggunakan konsep elektrokimia. Kaidah ini memerlukan larutan elektrolit (sebagai penghantar listrik) dan elektroda yang keduanya membentuk sistem sel elektrokimia. Jumlah elektroda yang digunakan dapat berjumlah dua atau tiga. Untuk dua buah elektroda, satu elektroda berfungsi sebagai substrat (katoda/elektroda kerja) yaitu elektroda yang 
akan dilapisi dan elektroda lain berfungsi sebagai elektroda kounter. Kedua elektroda dihubungkan dengan sebuah sumber catu daya.

Secara umum proses elektrodeposisi terbagi menjadi dua yaitu proses electroplating dan electroless. Proses elektroplating menggunakan batang elektroda sebagai sumber bahan pelapis sedangkan proses electroless menggunakan elektrolit sebagai sumber bahan pelapis [14]. Proses electroless memiliki beberapa keunggulan dibandingkan proses elektroplating meliputi keunggulan sifat fisik dan mekanik.

Proses elektrodeposisi melibatkan pengendapan partikel penguat pada lapisan logam matrik. Pengendapan melibatkan proses konveksi partikel pada permukaan substrat (katoda), penangkapan partikel secara mekanik maupun migrasi elektroforetik partikel kedalam logam matrik seperti yang ditunjukan pada Gambar 3 [15]. Secara umum tahapan proses pembentukan lapisan tipis komposit dengan kaidah elektrodeposisi adalah sebagai berikut: pertama adalah pembentukan partikel bermuatan melalui penyerapan ion dan surfaktan pada permukaan partikel. Selanjutnya partikel bergerak secara fisik menuju substrat melalui lapisan konveksi (proses transport) dan lapisan batas (proses difusi) dimana kedua proses dikendalikan oleh beda potensial antara kedua elektroda. Kemudian tahap akhir dari proses ini mengendapnya partikel pada logam matrik yang sedang tumbuh.

Kaidah elektrodeposisi biasa digunakan dalam pembentukan lapisan komposit nikel-senyawa nitrida seperti Ni-TiN. Kaidah ini mampu memberikan nilai kekerasan mikro hingga $150 \mathrm{HV}$ (pada beban 150 gramgaya) [16] ataupun $501 \mathrm{~kg} . g a y a / \mathrm{mm}^{2}$ [17], $1000 \mathrm{HV}$ [18], $902.8 \mathrm{HV} \mathrm{[16].}$

\section{PEMBAHASAN}

Hasil kajian menunjukan bahwa kekerasan lapisan Ni meningkat setelah dikompositkan dengan partikel keras TiN, AlN, SiC dsb [16,19,20] dimana peningkatan kekerasan terjadi seiring dengan peningkatan konsentrasi partikel keras. Namun demikian peningkatan kekerasan optimal terjadi pada kadar konsentrasi tertentu dari partikel penguat. Peningkatan kekerasan lapisan terjadi melalui kombinasi penguatan dispersi (Orowan) yang tersebar merata pada logam matriks maupun penguatan partikel yang membentuk butir halus pada batas butir logam matriks (Hall-Petch).

Secara umum uuran kristal logam matriks nikel lebih kecil ibandingkan dengan partikel nitrida [21] sehingga pada dasarnya partikel nitrida tidak mengendap didalam butir-butir logam matriks namun mengendap dikelilingi oleh beberapa butir logam matriks sehingga batas butir logam matriks akan digantikan oleh antar muka partikel-matriks. Pada kondisi ini partikel nitrida dapat memperkuat batas butir dan mencegah terjadinya deformasi plastis. Karena itu ukuran partikel nitrida dalam orde nano perlu dan penting diperhatikan untuk menjamin terbentuknya struktur nano. 


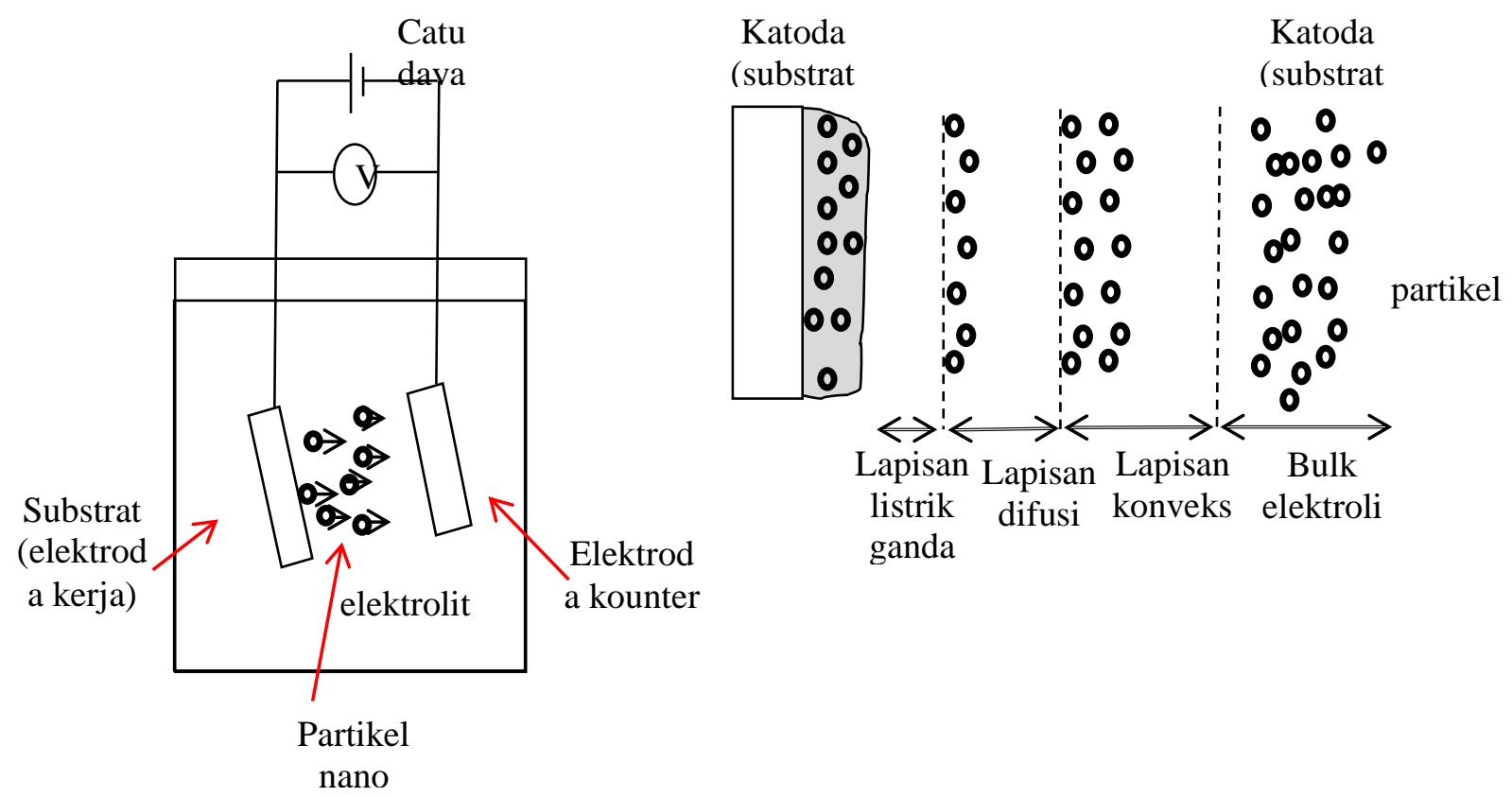

Gambar 2. Model skematik proses elektrodeposi pada sel elektrokimia [15]

Kekerasan lapisan komposit nikel-senyawa nitrida hasil deposisi secara umum terjadi akibat tegangan kompresif biaksial dengan kestabilan termal yang rendah sehingga nilai kekerasan turun drastis seiring dengan peningkatan suhu penggunaan hingga $650{ }^{\circ} \mathrm{C}$ [22]. Proses elektrodeposisi dapat dilakukan pada suhu dan energi yang relatif rendah sehingga memungkinkan tidak ada tegangan kompresif yang dihasilkan pada lapisan komposit yang dibentuk. Konsep umum dalam pembentukan lapisan komposit nitrida super keras dengan kestabilan termal yang tinggi adalah berdasarkan segregasi yang digerakan secara termodinamika dengan pengendapan stabil. Fluktuasi lokal komposisi fase campuran dari lapisan komposit mampu menurunkan nilai energi bebas Gibbs sehingga menghasilkan segregasi spontan tanpa perlu terjadinya pengintian fase lain [25].

Pembentukan lapisan komposit Ni-TiAlN/Si ${ }_{3} \mathrm{~N}_{4}$ menggunakan kaidah elektrodeposisi berpotensi memberikan nilai kekerasan yang tinggi melalui pembentukan struktur nano. Sistem lapisan keras ncTiAlN/a-Si ${ }_{3} \mathrm{~N}_{4}$ memberikan Partikel $\mathrm{Si}_{3} \mathrm{~N}_{4}$ merupakan partikel lembam (inert) yang tidak bereaksi dengan komponen lain [10] membentuk fase amorf yang mengelilingi fase kristal nano TiAlN yang sehingga berperan sebagai penghalang gerakan dislokasi ataupun retakan [12].

Pembentukan lapisan tipis multi fase nitrida juga telah dilakukan melalui sistem nc-TiN/a-

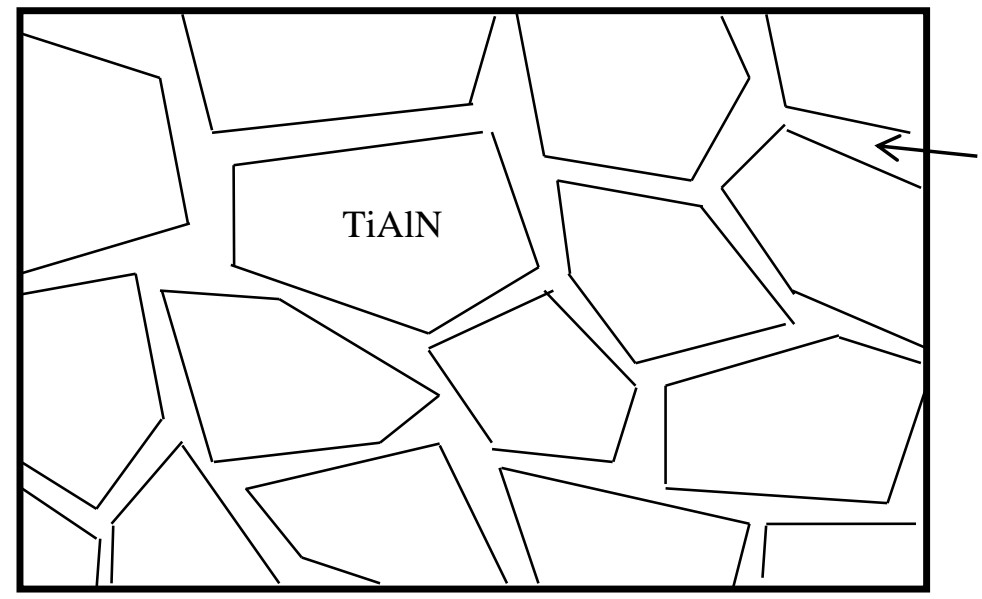

$\mathrm{Ni}-\mathrm{Si}_{3} \mathrm{~N}_{4}$

Gambar 3. Struktur nano lapisan komposit nikel-nitrida 
$\mathrm{Si}_{3} \mathrm{~N}_{4} / \mathrm{a}-\mathrm{TiSi}_{2}$ dan nc-TiN/a- $\mathrm{Si}_{3} \mathrm{~N}_{4} / \mathrm{nc}-\mathrm{TiSi}_{2}$ [23]. Kekerasan maksimum tercapai mana kala kristal nano TiN dilingkupi oleh lapisan mono $\mathrm{Si}_{3} \mathrm{~N}_{4}$ dan hal ini bergantung pada jumlah fraksi kristal nano $\mathrm{TiSi}_{2}$ yang terbentuk pada batas butir kristal TiN.

Namun demikian untuk kebutuhan beragam aplikasi, pencapaian nilai kekerasan yang sangat tinggi pada hakekatnya bukanlah satu-satunya tujuan. Sifat alamiah suatu material yang terlalu keras cenderung bersifat rapuh atau getas. Karena itu sifat tangguh material juga menjadi perhatian dalam rekayasa lapisan komposit superkeras [24]. Pembentukan lapisan komposit berbasis nikel-nitrida diharapkan selain mampu menghasilkan tingkat kekerasan yang tinggi namun juga diharapkan mampu memiliki ketangguhan.

\section{KESIMPULAN}

Sifat lapisan komposit nikel nitrida yang dibentuk melalui proses elektrodeposisi dipengaruhi oleh parameter prosesnya. Sifat lapisan komposit nikel-nitrida super keras dapat tercapai melalui pembentukan struktur nano melalui pengecilan ukuran butir kristal yang direkatkan oleh lapisan tipis amorf.

\section{REFERENSI}

[1] Sergio Neves Monteiro, Ana Lúcia Diegues Skury, Márcia Giardinieri de Azevedo, Guerold Sergueevitch Bobrovnitchii. Cubic boron nitride competing with diamond as a superhard engineering material - an overview J. MATER. RES. TECHNOL. 2013;2(1):68-74.

[2] Paul W. May. Diamond thin films: a 21st-century material Phil. Trans. R. Soc. Lond. A (2000) 358, 473-495.

[3] C.-H. Ma, J.-H. Huang1, Haydn Chen. Texture evolution of transition-metal nitride thin films by ion beam assisted deposition. Thin Solid Films 446 (2004) 184-193.

[4] S. Menzel, Th. Gobel, K. Bartsch, K. Wetzig. Phase transitions in PACVD-(Ti,Al )N coatings after annealing. Surface and Coatings Technology 124 (2000) 190-195.

[5] Shiqiang Hao, Bernard Delley, Stan Veprek, and Catherine Stampfl. PHYSICAL REVIEW LETTERSPRL 97, 086102 (2006).

[6] S. Veprek and M. Jilek. Superhard nanocomposite coatings. From basic science toward industrialization. Pure Appl. Chem., Vol. 74, No. 3, pp. 475-481, 2002.

[7] Stan Vepreka. The search for novel, superhard materials J. Vac. Sci. Technol. A 17.5., Sep/Oct 1999.

[8] Chung Wan Kim, Kwang Ho Kim. Anti-oxidation properties of TiA1N film prepared by plasma-assisted chemical vapor deposition and roles of A1Thin SoLid Fihns 307 (1997) 113119.

[9] E. Budi dkk. Pembentukan lapisan tipis keras nanokomposit menggunakan teknik elektrodeposisi untuk perlindungan bahan terhadap aus dan korosi. Laporan Penelitian AUPT 2014. Jurusan Fisika FMIPA Universitas Negeri Jakarta. 2015.

[10] Xiaopeng Lu, Carsten Blawert, Nico Scharnagl, Karl Ulrich Kainer. Influence of incorporating Si3N4 particles into the oxide layer produced by plasma electrolytic oxidation on AM50 Mg alloy on coating morphology and corrosion properties. Jurnal of Magnesium and Alloys 1 (2013) 267e274.

[11] P. Holubar, M. Jilek, M. Sima. Present and possible future applications of superhard nanocomposite coatings. Surface and Coatings Technology 133-134 (2000) 145-151.

[12] S. Veprek. Conventional and new approaches towards the design of novel superhard materials. Surface and Coating Technology 97 (1997) 12-22 
[13] Shujiang Geng, Fuhui Wang, Sam Zhang. High temperature oxidation behavior of a sputtered pure Ninanocrystalline coating at 700-900 C. Surface and Coatings Technology 167 (2003) 212-216.

[14] Jothi Sudagar, Jianshe Lian, Wei Sha. Electroless nickel, alloy, composite and nano coatings - A critical review. Journal of Alloys and Compounds 571 (2013) 183-204.

[15] F. C. Walsh and C. Ponce de Leon. REVIEW A review of the electrodeposition of metal matrix composite coatings by inclusion of particles in a metal layer: an established and diversifying technologyTransactions of the IMF 2014 VOL 92 NO 2.

[16] Fafeng Xia, WeixianYue, Jindong Wang, Chao Liu, Famei Wan, YangLi. Synthesis of Ni-TiN composite nanocoatings by magnetic pulse current depositionCeramicsInternational41 (2015)11445-11448.

[17] Magdy A.M. Ibrahim, F. Koolil and Saleh N. Alamri. Electrodeposition and Characterization of Nickel-TiN Microcomposite Coatings Int. J. Electrochem. Sci., 8 (2013) $12308-12320$.

[18] Minzheng Jiang, Chunyang Ma, Fafeng Xia, Yue Zhang. Application of artificial neural networks to predict the hardness of Ni-TiN nanocoatings fabricated by pulse electrodeposition. Surface \& Coatings Technology 286 (2016) 191-196.

[19] A.Abdel Aal, M. Bahgat, M. Radwan. Nanostructured Ni-AlN composite coatings. Surface \& Coatings Technology 201 (2006) 2910-2918.

[20] Pradeep Devaneyan. S, T. Senthilvelan. Electro Co-deposition and Characterization of $\mathrm{SiC}$ in Nickel Metal Matrix Composite Coatings on Aluminium 7075. Procedia Engineering 97 ( 2014 ) 1496 - 1505.

[21] Manoj Kumar Tripathi, V.B. Singh. Properties of electrodeposited functional NiFe/AlN nanocomposite coatings Arabian Journal of Chemistry (2015).

[22] P. Karvankova, H.-D. Mannling, C. Eggs, S. Veprek. Thermal stability of ZrN-Ni and $\mathrm{CrN}-\mathrm{Ni}$ superhard nanocomposite coatings. Surface and Coatings Technology, 146-147 (2001) 280-285.

[23] S. Veprek, A. Niederhofer, K. Moto, T. Bolom, H.-D. Mannling, P. Nesladek, G. Dollinger, A. Bergmaier. Composition, nanostructure and origin of the ultrahardness in ncTiNra-Si N ra- and nc-TiSi nanocomposites with $342 H$ s80 to G105 Gpa. Surface and Coatings Technology. 133-134 (2000) 152-159.

[24] Sam Zhang, Deen Sun, Yongqing Fu, Hejun Du. Recent advances of superhard nanocomposite coatings: a review. Surface and Coatings Technology 167 (2003) 113-119.

[25] Stan Vepreka. Towards the understanding of mechanical properties of super- and ultrahard nanocomposites. J. Vac. Sci. Technol. B 20.2., Mar-Apr 2002.

[26] F.F. Xi, C. Liu, F. Wang, M.H. Wu, J.D. Wang, H.L. Fua, J.X. Wang. Preparation and characterization of Nano Ni-TiN coatings deposited by ultrasonic electrodeposition. Journal of Alloys and Compounds 490 (2010) 431-435. 
